\title{
Public Awareness and Disaster Risk Reduction: Just-in-Time Networks and Learning
}

\author{
Ali Ardalan, $\mathrm{MD}, \mathrm{PhD} ;{ }^{1}$ Faina Linkov, $\mathrm{PhD} ;{ }^{2}$ Eugene Shubnikov, $\mathrm{MD} ;{ }^{3}$ \\ Ronald E. LaPorte, $\mathrm{PhD}^{2}$
}

1. Health in Emergency and Disaster Department, Institute of Public Health Research, Tehran University of Medical Sciences, Tehran, Iran

2. University of Pittsburgh, Pittsburgh, Pennsylvania USA

3. Institute of Internal Medicine, Novosibirsk, Russia

\section{Correspondence:}

Ali Adalan, MD, PhD

Assistant Professor

Health in Emergency and Disaster Department

Institute of Public Health Research Tehran University of Medical Sciences Tehran, Iran

E-mail: aardalan@gmail.com

Keywords: disasters; distance education; e-learning, risk reduction

\section{Abbreviations: \\ JIT $=$ just-in-time}

Received: 10 April 2007

Accepted: 12 October 2007

Revised: 17 December 2007

Web publication: 20 June 2008

\begin{abstract}
Improving public awareness through education has been recognized widely as a basis for reducing the risk of disasters. Some of the first disaster just-in-time (JIT) education modules were built within 3-6 days after the south Asia tsunami, Hurricane Katrina, and the Bam, Pakistan, and Indonesia earthquakes through a Supercourse. Web monitoring showed that visitors represented a wide spectrum of disciplines and educational levels from 120 developed and developing countries. Building disaster networks using an educational strategy seizes the opportunity of increased public interest to teach and find national and global expertise in hazard and risk information. To be effective, an expert network and a template for the delivery of JIT education must be prepared before an event occurs, focusing on developing core materials that could be customized rapidly, and then be based on the information received from a recent disaster. The recyclable process of the materials would help to improve the quality of the teaching, and decrease the time required for preparation. The core materials can be prepared for disasters resulting from events such as earthquakes, hurricanes, tsunamis, floods, and bioterrorism.
\end{abstract}

Ardalan A, Linkov F, Shubnikov E, LaPorte RE: Public awareness and disaster risk reduction: Just-in-time networks and learning. Prehospital Disast Med 2008;23(3):286-288.

\section{Introduction}

Improving public awareness through education has been recognized widely as a basis for reducing the risk for disasters. ${ }^{1} \mathrm{~A}$ just-in-time (JIT) educational strategy can be used as a means for rapid dissemination of disaster knowledge and education within days, if not hours, during or after an event. Media such as television and newspapers, often show the dramatic components of the disaster to "pump up ratings" and to be critical of governments. Often, the media only scare rather than educate the public by selecting only the most sensational aspects for coverage. At the same time, communities and individuals must learn about and from the disaster. Who can be trusted more than educators, academics, and scientists to be the source of this education shortly after a disaster?

The nature of disasters draws public attention. No one knows when and where the next tsunami, earthquake, or terrorist attack will happen. Their sudden onset and unpredictable outcomes raise many questions that cannot be predicted beforehand. What is an earthquake? Where can my children be safe in the aftermath of a fire? How can I find the status of my relatives? What schools are open? How devastating and deadly is the hurricane? How many people are in need? Who are the victims? What should we do with the bodies? How can I help? How will business be affected? Will there be another quake? There often is a combination of uncertainty, stress, and fear. ${ }^{2}$ This is bad for the economy, health of a population, and recovery efforts. 


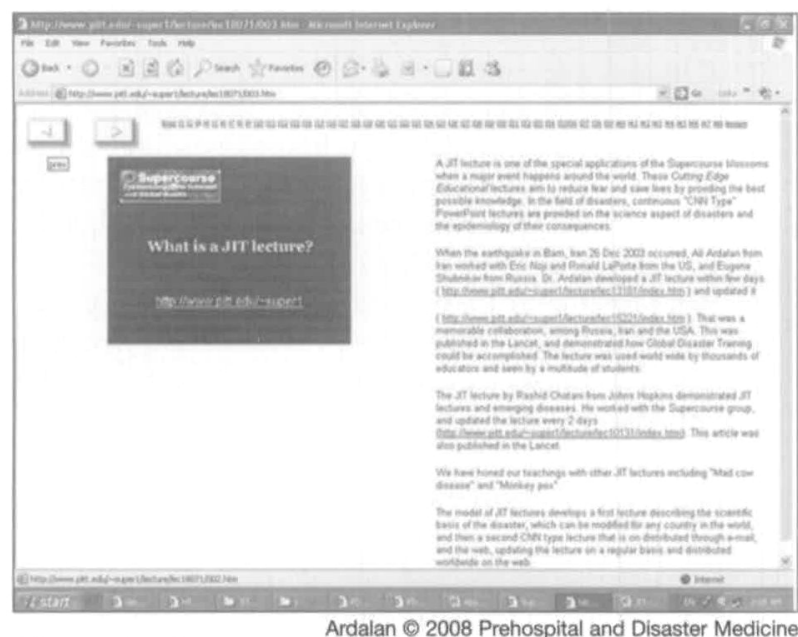

Figure 1-Just-in-time (JIT) education

The goal of disaster JIT education is to increase the public awareness of the natural and man-made hazards, vulnerabilities, and risk information. It teaches people that earthquakes or tsunamis are not acts of God, and that risks can be minimized in order to live safely. Using trusted educators, the JIT educational strategy can be applied through any feasible means of communication, and can cover an affected community, a country, and the world. Depending on the severity of a disaster, damage to structures, and the availability of communication facilities, it can be applied at the scene of a disaster as well to help create and/or maintain an effective response and recovery. A wide variety of communication methods can be used to educate, ranging from simply designed pamphlets, banners, and/or radio messages, to advanced e-learning programs. The golden time for public interest must not be missed. This article focuses on an Internet-based rapid onset educational system and proposes the elements of a JT preparedness plan.

\section{JIT Educational Modules}

Some of the first disaster ЛT education modules (Figure 1) were built three to six days after the south asia Tsunami (Figure 2), Hurricane Katrina, and the Bam, Pakistan, and Indonesian earthquakes. Based on the Supercourse-an open-source library of about 3,200 PowerPoint lectures on prevention displayed on the Web, supported by 45 mirror sites-a group of multi-national, multi-disciplinary scientists worked together through the Internet to develop the lectures just a few days after the aforementioned events and continuously updated them. ${ }^{3}$ The PowerPoint (Microsoft Inc., Redmond, WA) files, which were no larger than 700 kilobytes $(\mathrm{KB})$, were downloadable without charge. The lectures used recent events as examples to teach how communities and countries can prevent and mitigate the risk of disasters. To be pro-active, the potential users were informed about the existence of such lectures through a pre-established, Web-based network of about 30,000 public health professionals from 174 countries who were asked to pass the lectures on to at least five other educators. Some

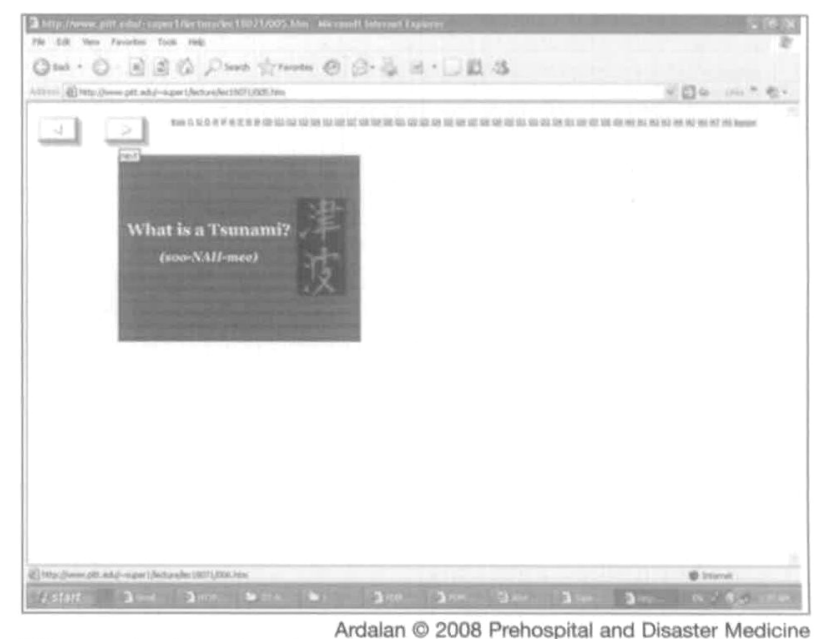

Figure 2-Just-in-time (JIT) South Asia tsunami lecture

lectures were translated into Spanish, Chinese, and Arabic in order to minimize the time between lecture development and classroom presentation. The Web monitoring showed that ЛT lectures were some of the most watched/downloaded lectures as measured by Google page rankings. Google page rankings are the primary measures of Web impact and utilization, which determine where the site is seen in a Google search. Thus, for instance, if a Website has a page rank of four, it will be seen fourth in a Google search. In general, for most of the JT lectures, the page rankings are in the top 20, as the Supercourse tsunami lecture was $99.99 \%$ more likely to be viewed than all other tsunami lectures available on the Web. ${ }^{4}$ Monitoring of the Web statistics showed that visitors hailed from a wide variety of disciplines and educational levels, from 120 countries. The actual number of those that viewed the lectures is much greater, as a large number of the PowerPoint files were downloaded for teaching purposes, and were watched by students in the class. Thus, Web hits are a poor indicator of the actual magnitude of dissemination.

To be the most effective, template JT education must be prepared before an event, focusing on developing core materials about the nature of a specific hazard and how to prevent or mitigate the related risk for an event or the damage and loss of functions that may result. The core material would be customized rapidly based on the information received from a recent disaster. The recycling process of the materials would improve the quality of each lecture, and reduce the production time for new lectures. The core materials can be prepared for the most frequent and devastating hazards, such as earthquakes, hurricanes, tsunamis, floods, and acts of terrorism.

Building a network of experts beforehand is a crucial part of the preparedness in order to develop, update, and disseminate these materials. The network could consist of experts from different disciplines (public health, risk management, epidemiology, meteorology, seismology) at the international, national, and local levels. During the Pakistan and Indonesian earthquakes, scientists from affected coun- 
tries joined the network and provided the most reliable available information, and also distributed the lectures to other experts and faculty members. With customized lectures, the network can "spring into action" to produce a lecture within hours. This network has helped target a wide range of audiences; educators, professionals, managers, and policy-makers.

A large network can be used to access expert knowledge, in which could be answered by reaching leading global experts, who then can provide relevant information and suggest courses of action. With this approach, the parent network can be used to find global experts with specific expertise, which is needed for any particular form of disaster (e.g., an expert on asbestos plumes in a fire, leading experts on structural engineering for hotels).

Even small-scale disasters draw public interest. For instance, a non-destructive earthquake measuring 5.5 on the Richter scale, which has shaken a wide area of a country, is enough to make people fearful and attract them to a television for hours, hoping to hear information about the possibility of a strong aftershock. This time could be used to teach them how to make their building earthquakeresistant, in which areas it is safe to construct buildings, and how to minimize the risk to non-structural elements in their homes or work place. Many opportunities are lost each day, and experts can fill this informational gap. Local JIT lectures can be prepared for house fires, limited flooding, and/or food poisoning, each designed by experts and used as teaching materials for all of us to help people learn about the facts of these kinds of "mini" disasters.

New developments in information technology are on the horizon. Lectures can be disseminated through cell phones and other hand-held media devices. Just-in-Time lectures can be posted on the video Website YouTube, as can virtual disaster drills.

Building disaster networks using JIT educational strategy seizes the opportunity of public interest to teach and find national and global expertise in hazards and risk information. Larger events mean larger interest. Although it can be applied by any means of communication, the Internet is an efficient approach to provide educators with scholarly, user-friendly, low-cost, and online-offline training materials. The increasing trend in the use of the Internet access, cellular phones, and virtual communication even in developing countries can be the backbone of education now and even more so in the future.

\section{References}

1. International Strategy for Disaster Reduction: Living with Risk: $A$ Global Review of Disaster Reduction Initiatives. New York and Geneva: United Nations, 2004.

2. LaPorte RE, Sauer FW, Saad R, Shubnikov E: Bioterrorism and the epidemiology of fear. Lancet Infectious Disease 2002;2(6):326.
3. Global Health Network Supercourse. Available at http://www.pitt. edu/ super1. Accessed 03 October 2007.

4. Shubnikov E, LaPorte RE: What does page ranking teach us. Available at http://www.pitt.edu/ super1/lecture/lec26131/index.htm. Accessed 03 October 2007.

5. Linkov F, Ardalan A, Dodani S, et al: Building just-in-time lectures during the prodrome of Hurricanes Katrina and Rita. Prebospital Disast Med 2006;21(2):132. 